\title{
Counterfactuals, Thought Experiments and Singular Causal Analysis in History
}

I (and Abstract)

Thought experiments are ubiquitous in science but especially prominent in domains in which experimental and observational data are scarce. Thus, for instance, when the causal analysis of singular events such as the causes of a particular war, of the rise of a culture or of the economic performance of a country in a specific historical period is at stake. A longstanding tradition in history that goes back to Max Weber answers questions about the causes of singular historical events by means of 'What-if?' counterfactuals. The aim of this paper is twofold. First, I want to give a descriptive account of this widely used method in history. Second, I argue that historians who follow this method examine difference makers rather than causes in the philosophers' sense, despite their surface rhetoric. I conclude that although difference making is neither necessary nor sufficient for causation in the philosophers' sense, looking for difference makers is more consistent with the historians' more ultimate purposes.

II

In one of his most widely read essays, 'Objective Possibility and Adequate Causation in Historical Explanation' , Max Weber introduced the basic procedure for singular causal analysis as follows (Weber 1949/1905: 171):

Rather, does the attribution of effects to causes take place through a process of thought which includes a series of abstractions. The first and decisive one occurs when we conceive of one or a few of the actual causal components as modified in a certain direction and then ask ourselves whether under the conditions which have been thus changed, the same effect... or some other effect 'would be expected'.

In other words, in order to assess whether some event ('causal component') $f$ (where $f$ is a set that can but does not have to be a singleton) caused an event of interest $\phi$, the historian mentally removes $f$ from the actual course of history and asks whether this removal would have made a difference to the occurrence of the event of interest $\phi$, or: to know if $f$ causes $\phi$, one needs to know whether 'had $f$ not been, $\phi$ would not have been' is true.

This first sketch requires a more exact formulation in at least two respects. First, one needs to spell out how precisely $f$ is to be removed from the actual course of history. Second, one needs an account of how to know what 'would have to be expected' about $\phi$ upon the removal of $f$. In his essay Weber is uncharacteristically silent about the first issue; about the second, he says (ibid.: 173):

This means that we so decompose the "given" into "components" that every one of them is fitted into an "empirical rule"; hence, that it can be determined what effect each of them, with others present as "conditions,: "could be expected" to have, in accordance with an empirical rule. A judgment of "possibility" in the sense in which the expression is used here, means, then, the continuous reference to "empirical rules" (Erfahrungsregeln).

Instead of trying to determine what precisely Weber could have meant by these words, and how he could have addressed the first question, in what follows I examine in detail three contemporary attempts to evaluate 'what-if' counterfactuals and come back to the two issues thereafter. 
The counterfactual claims that will be examined are the following:

- Had the Greeks not won against the Persians at Salamis, Western civilisation would not have become dominant in the world.

- Had Chamberlain confronted Hitler at Munich, World War II would have been no worse and probably better.

- Had Kennedy shown more resolve prior to the Cuba crisis, Khrushchev would not have deployed missiles.

Let us consider each in turn.

Themistocles and Xerxes. In trying to explain why 'Western values' (such as, say, free speech, political equality, individual property) came to dominate in the world, one might ask whether any events in the history of the rise of the West were decisive in the sense that without them, the world would have looked dramatically different. Victor David Hanson 2006 argues that the Greek victory against the Persians at Salamis in $480 \mathrm{BC}$ was just such an event. At the time, the armies of Persian king Xerxes had occupied Asia Minor, several of the islands in the Aegean Sea and a considerable part of Attica. Athens had been abandoned by the Greeks and burned down. Themistocles, the Athenian leader, convinced the Athenians and their allies that only a fight at sea and only in the narrow straits of Salamis - rather than a confrontation of the infantry at the Isthmus of Corinth, as was proposed by the Peloponnesians - could stop the Persians.

Due to a ruse planted by Themistocles, the Persians believed that the Greek fleet was retreating and followed into the straits. Because of its narrowness, the Persians could not take advantage of their numerical superiority. Moreover, the Greek ships were more mobile than the Persian ships and better fitted to ram and sink enemy ships. The Persians, trapped by the Greek navy, lost half of its ships and some one hundred thousand sailors. This battle marked the turning point in the Persian wars. Xerxes marched homewards with some of the survivors and never returned to the Greek mainland. Within a year the Athenians could reoccupy Attica permanently and pushed the Persians into Boetia in the north.

Hanson breaks his argument in favour of the claim that the Battle of Salamis was instrumental in the rise of Western civilisation into three counterfactuals (50-1):

(a) had not Themistocles planned and led the Athenians' attack, the Greeks would have lost the battle at Salamis; (b) had Athens not led the coalition and chosen to fight at sea off Salamis, the Greeks would have lost the Persian wars; and (c) had the Greeks not won the Persian Wars, Hellenic civilization would have been absorbed by the Persians and Western culture in turn would have been aborted in its infancy or at least so radically altered as to be nearly unrecognizable.

To argue for the truth of each of these claims, Hanson presents evidence to the effect that (among other things):

(a) a battle at land could not have been won by the Greeks; in particular, an attempt to protect the Peloponnese by fortifying the Isthmus of Corinth would have been frustrated by Persian ships landing to the rear along the coast of the Peloponnese as well as a superior Persian infantry; Themistocles' shrewdness (apparently he misled both Persians as well as Athenian allies) was deci- 
sive in making the Persians battle at Salamis and the way the battle was fought: no alternative Greek leader seems likely to have designed that particular strategy;

(b) Salamis, not Marathon (fought a decade earlier) or any other pre-Salamis clash, stopped the Persians from advancing; later battles would not have been won had it not been for Salamis; no fight at land could have been won by the Greeks; the strait at Salamis provided ideal and unique tactical conditions for outnumbered Greek fleet;

(c) although the Persians granted conquered tribes limited autonomy, mostly in religious and administrative matters, important Hellenic values such as political freedom and property rights would have clashed with the autocratic culture of the Persian empire and most certainly been suppressed; these essential Hellenic values at the time could only have been found in Greece; had the Athenians succumbed, the remaining unoccupied parts of Greece such as Sicily could not have sustained Hellenic culture by itself.

Chamberlain and Hitler. Parallel with Hitler's rise to power in 1933, Britain reconsidered its foreign policy. A threat was perceived from National Socialism in Germany, Fascism in Italy and Japanese expansionism. Germany was seen as the major security hazard for Britain, and the strategy to deal with her was a mixture of appeasement and deterrence. On the one hand, some of Germany's complaints were regarded as legitimate and a wider European settlement was aimed at; on the other, Britain tried to rearm in order to confront German demands from a position of strength.

In the Baldwin cabinet, in which Neville Chamberlain was chancellor of the exchequer, this policy was formulated and implemented, and Chamberlain played an important role in the process. However, when he succeeded Baldwin as prime minister, Chamberlain changed the strategy to one of appeasement alone and stopped regarding rearmament as a priority.

This much was apparent from Britain's role in the Anschluss, the forced union of Austria with Germany. The Chamberlain cabinet thought Austria was dispensable, found Austria's chancellor to be unreasonably inflexible in meeting what they regarded as legitimate German demands and saw many Austrians supportive of the union with Germany.

The integration of Germans across Europe being the stated goal, Hitler turned his attention the Sudetenland. While Britain regarded the Czechoslovakia itself as dispensable, the situation was highly relevant to Britain's security concerns because France had a treaty with Czechoslovakia obliging the country to help in case Czechoslovakia was attacked. Further, Russia had agreed to join France in defending Czechoslovakia and Britain had a pact with France.

Britain's predominant goal was to avoid a war between the major European powers. Among the stated reasons were that Britain was weakened by the First World War, both in terms of manpower as well as military strength, and Chamberlain's belief in his own diplomacy and in Hitler.

Of course we know that Britain did not reach its predominant goal. Rather, only five months after entering into the Sudetenland, as allowed by the Munich Agreement, Hitler's troops occupy the remainder of the Czechoslovakia and another six month later the Second World War began with Germany invading Poland.

Yuen Foong Khong tries to answer the question 'Would history have turned out differently if Britain had acted more resolutely in the face of Hitler's Sudetenland demands?' (Khong 1996: 95). In particular, the focus of his article is on examining the plausibility of the antecedent ('Could Britain have 
acted more resolutely?') and on whether had the antecedent been true it would have followed that Hitler would have backed down or that the Second World War would (or might) have been avoided.

Khong demonstrates that an anti-appeasement policy was indeed possible. It is well documented that Anthony Eden, Duff Cooper and Winston Churchill defended a more hawkish stance against Germany (at least in 1938, the time of the Munich Agreement) and occupied positions within British politics that make it conceivable that one of them could have been Prime Minister at the time of the Munich Agreement or that they could have had a stronger influence on the foreign politics of the Chamberlain cabinet. Moreover, Hitler knew that with any of the three as PM, Britain would assume a very different stance against Germany.

Let us then move on to Khong's evaluation of the consequence of a more hawkish British stance. In 1945 Churchill popularised the theory that had Britain confronted Hitler in 1938, his domestic enemies would have staged a coup d'état. According to this theory Hitler's opponents, military officers who felt that Germany was not ready for war, were ready to attack, just waiting for an outside signal. An alternative theory is that a coup would only have been triggered by an early war between BritainFrance-Czechoslovakia and Germany. This, however, was a distinct possibility too as at least Churchill was ready to fight in case deterrence failed. Either way it is very likely that the course of European history would have been very different had Hitler been disposed of as early as 1938.

There are also some indications that Hitler was responsive to tough talk. For instance, when French prime minister Daladier threatened Hitler with ending the Munich talks immediately should his intention be to destroy Czechoslovakia and annex it to Germany, Hitler backed down to deny that the plan was to annex any Czechs.

There are thus three possibilities: Hitler would have backed down; Hitler's enemies within Germany would have staged a coup d'état and disposed of him (with or without an earlier war); or there would have been an early war with Hitler in power. Assuming that the first two possibilities would have been better than the actual course of history, a final question is what Europe is likely to have looked like had there been a war in 1938 instead of 1939. At least some historians argue that the earlier war would have been preferable, among other things because Czechoslovakia would have been intact and on the Allies' side.

In summary, Khong argues that even if a war would have unfolded parallel to the events that actually happened a year later, 'confrontation would have been preferable to appeasement because its worst outcome would have been "no worse than the course of 1939"” (op. cit:: 117).

Kennedy and Khrushchev. The Cuban Missile Crisis too is a historical episode that, or so some historians argue, could have been avoided had one of its main actors, in this case John F. Kennedy, had shown greater resolve. The crisis was a military confrontation between the U.S. and the Soviet Union over a number of ballistic missiles the USSR had deployed in Cuba in September 1962 in response to an earlier instalment of 15 intermediate-range ballistic missiles in Turkey that had Moscow within their reach. Historians and political actors, including the main actors Kennedy and Khrushchev, have formulated a large number of counterfactual statements about the crisis, including (Lebow and Gross Stein 1996: 124-5):

- 'Had Kennedy displayed greater resolve prior to the crisis, Khrushchev would not have sent missiles to Cuba.' 
- 'Had the United States attacked the missile bases, the Soviet Union would have responded with military action of its own against the States, probably in Berlin or Turkey.'

- 'Had the United States attacked the missile bases, the Soviet Union would not have responded with military action of its own.'

- 'Had the United States not stood firm on Cuba, Khrushchev would have been tempted to engage in new challenges, most likely in Berlin, that would have had greater risk of nuclear war.'

Analysing these and other counterfactuals the Richard Ned Lebow and Janice Gross Stein find the empirical basis for many of the assertions wanting. Here I want to take a closer look at two problems in particular. Examining the first counterfactual about Kennedy's resolve prior to the crisis, Lebow and Stein argue that it wouldn't really have made sense for Kennedy to issue a warning before the conventional build up in Cuba began because he neither had reason to suspect a missile deployment nor did he have a domestic incentive as elections were still months away. That is, Lebow and Stein think that in order to evaluate the counterfactual, we need to examine what else, in the antecedent's past, would have had to be different in order for the counterfactual antecedent to appear possible or likely.

David Lewis thinks that counterfactuals are vague in such cases. His example is borrowed from Peter Downing (Lewis 1979: 456):

Jim and Jack quarrelled yesterday, and Jack is still hopping mad. We conclude that if Jim asked Jack for help today, Jack would not help him. But wait: Jim is a prideful fellow. He never would ask for help after such a quarrel; if Jim were to ask Jack for help today, there would have to have been no quarrel yesterday. In that case Jack would be his usual generous self. So if Jim asked Jack for help today, Jack would help him after all.

Lewis then argues that the 'standard resolution' of such vague counterfactuals is non-backtracking: in order to evaluate the counterfactual, we do not go back in history and ask 'what would have to be that...'. Only in special contexts (for example, in order to allow a conversation partner to be right) does the non-standard, backtracking resolution apply. Contrarily, Lebow and Gross Stein ask just that question: what conditions would have to have been present in order for Kennedy to show greater resolve? Those conditions that would have made Kennedy show resolve were not present historically, and thus they regard the counterfactual antecedent as inadmissible.

Second, depending on how the antecedent is precisely implemented, whether or not the consequent is likely to be true might change as well. Consider the second and third counterfactual about what would have happened had the U.S. attacked the Cuban missile bases. Lebow and Stein argue (139):

\footnotetext{
Khrushchev's response would probably have been context dependent. An air strike that destroyed Soviet missile sites and killed several hundred Soviet soldiers might have provoked a different response than air attacks followed by an invasion that caused tens of thousands of Soviet casualties and toppled the Castro government.
}

The authors conclude that since Khrushchev's response would also have been influenced by the reaction of the NATO allies and the intensity of pressure within Soviet leadership to retaliate and these factors and their interaction cannot be assessed, the truth of the corresponding counterfactuals is simply not knowable. 
Coming back to our two issues, let us first address the question of implementing the antecedent. The historians' theory of singular causation clearly bears superficial resemblance to David Lewis's theory (e.g., Lewis 1973) but it differs significantly on the method of evaluating the counterfactual. In Lewis's scheme, a counterfactual antecedent is implemented by 'miracle': by a minimal incision that breaks all causal laws that have the antecedent event as effect and brings about the event without itself having causal antecedents (or, more accurately, without causal antecedents that may affect the consequent).

Historians also use a 'minimal re-write rule' (cf. Tetlock and Belkin 1996) but it means something entirely different. It requires that the antecedent not falsify much of what we know about the actual cause of events given what we know about causal generalisations. When implementing a counterfactual antecedent, the historian thus asks what conditions would have to be present in order for the antecedent to follow from these conditions, and whether these conditions were likely. In the first example the question is, what would have made likely that the Greeks lost the battle at Salamis? Hanson mentions a variety of conditions: for instance, a different strategy, or the non-fulfilment of the chosen strategy due to the Persians' failure to fall for for the ruse, a different leader, less support from the Athenian's allies and so on. Importantly, for Hanson it matters very much how a Greek defeat would have come about: the antecedent is not implemented by miracle.

Similarly in the second and third case. Khong does not construct a fictional scenario in which Chamberlain pursues a confrontational course and nothing else changes. For this to happen too much else would have to be different, as Chamberlain was too confident in the rightness of the appeasement policy and hawks in his cabinet had been silenced. He therefore goes back in time and wonders whether it is conceivable that someone else would have been Prime Minister and whether that someone would have pursed a more confrontational strategy. And indeed, he finds that it is entirely possible that a different Prime Minister would have taken Chamberlain's stead and of the possible candidates at least three - Eden, Cooper, Churchill - were known hawks.

The third case shows that a counterfactual is inadmissible unless the conditions under which the antecedent would have been likely to obtain are present. Lebow and Gross Stein argue that it does not make sense to ask what would have happened had Kennedy shown greater resolve because there was no reason for him to do so: neither did he have intelligence to the effect that the Soviets were about to deploy missiles nor was he under internal pressure for example due to pending elections (Lebow and Stein 1996: 129). Were we to evaluate the counterfactual we would have to change these conditions; however, moving elections or altering what Kennedy could know at the time would require too much historical re-writing.

To address the second issue, we can observe that once the antecedent is implemented, the consequent is judged by the historian to obtain on the basis of what else he knows about the historical context as well as certain 'informal rules' of human behaviour. The Persians effectively suppressed Greek culture (or eliminated the population altogether) in other parts of Greece subjugated by them such as settlements in Asia Minor and the Ionian islands. We can thus suspect that they would have done the same with the Athenians if the latter had succumbed. Similarly, Khong uses a piece of evidence about Hitler's reaction to Daladier's threat to end the negotiation to argue that Hitler had a certain disposition - 'being responsive to tough talk' - which in turn makes it plausible that Hitler could have backed down, if only Britain had been firm. It is important to note that the generalisations invoked are not strict laws or even explicit models of human behaviour such as rational choice models. Rather, they are rough generalisations of the kind 'people continue to act on those behav- 
ioural patterns they have manifested in the past' or 'people do what they say they would unless there is a good reason not to' and so on.

The historians' counterfactual thus differs from Lewis's in two major ways. First, the semantics of implementation differ in important ways. For the historian, a counterfactual antecedent is assertable only if causal conditions were present such that the antecedent was likely to obtain (even though it did not, as far as we know, obtain). Let us call such an antecedent historically consistent (cf. Tetlock and Belkin 1996: 23-5). Second, Lewis formulated truth conditions for counterfactuals and could thus invoke laws of nature independently of whether these laws are known of not. Historians are less interested in truth and more in whether or not a given claim can reasonably be asserted and therefore evaluate a counterfactual in terms of what is know rather than what is the case. Counterfactuals are therefore assertable relative to the evidence at hand and the generalisations believed by an individual historian.

Summarising, we can define:

Let $H$ be a historian with beliefs about the relevant evidence and causal generalisations $B$, and $C$ a historical context such that $\neg f$.

Relative to $B$, the counterfactual ' $\neg f \square \rightarrow \neg \phi$ ' is assertable iff

- $f, \phi$ obtained

- $\neg f$ is historically consistent and precise enough to allow of a judgement regarding $\neg \phi$

- $\quad H$ judges $\neg \phi$ to obtain in $C$.

Returning to the issue of singular causation we may further define:

Weber-causation. ' $f$ was a cause of $\phi$ ' is assertable iff ' $\neg f \square \rightarrow \neg \phi$ ' is assertable.

How successful is Weber-causation as a theory of causal inference? Among philosophers it is a generally accepted pillar of truth that, if counterfactuals are to be used as stand-ins for causal claims, they have to be non-backtracking. That is, the counterfactual antecedent must be implemented such that none of its causes makes a difference to the counterfactual consequent. In Lewis's case, the antecedent is implemented by (a) breaking the laws that have the putative cause-event as an effect just before the putative cause event would have occurred (b) breaking only these laws and (c) bringing the alternative event about by miracle, without any causal antecedent of its own.

Virtually all historical counterfactuals I have had a chance to examine backtrack. The examples discussed here are no exceptions. Now, that would not matter much if the backtracking was merely in time. What matters is whether or not the changed causal antecedent of the putative cause event is a cause of the putative effect event on a route that does not go through the putative cause. This is what Lewis's conditions aim to prevent. But the historians' account cannot rule out situations of this kind and therefore the account is subject to counterexamples.

Consider Britain's appeasement policy as the putative cause event. Khong implements it in explicitly backtracking fashion by removing Chamberlain and making someone else Prime Minister. But likeli- 
hood and manner of war surely depends on who is Prime Minister quite independently of Britain's stance on the Sudetenland. For instance, one reason Chamberlain gave for pursuing the strategy he had chosen was that Britain wasn't rearmed sufficiently to go to war with Germany. However, the slow pace of rearmament was partly Chamberlain's own doing. Hence, we can expect that if, say, Churchill had been Prime Minister, it is likely that Britain's military would have been stronger, which, in turn, could have affected likelihood and manner of the Second World War.

But, as is well known, if the counterfactual is backtracking in this sense, the associated causal claim can be judged wrongly. Suppose $f$ is not a cause of $\phi$ but $g$ is, and $g$ is also a cause of $f$. If one implements $\neg f \square \rightarrow \neg \phi$ by changing $g$, the counterfactual will be true although ex bypothesi $f$ does not cause $\phi$. Weber-causation is therefore not sufficient for causation.

A notorious problem for counterfactual theories of causation is that of 'redundant causation', which obtains when several alternative events compete to cause an effect. Actual causes do not always make a difference to the effect, namely when there is another event that would have caused the effect were it not for the operation of the actual cause. Weber-causation suffers from this defect too.

Suppose, for instance, that as a matter of fact the Battle of Salamis led to the rise of Western civilisation. The Persians were defeated, Hellenism could thrive and, as it happened, influence Rome and through it the subsequent powers in Europe and later in the Americas. But suppose further that had the Athenians escaped instead and settled in Sicily, they would not have been molested by the Persians and Hellenism would have thrived anyway - with a epicentre shifted slightly to the West. Then the Battle would have been the actual cause but no Weber-cause.

Historians go through great pains to make sure that the putative cause event indeed makes a difference to the effect. Hanson, for instance, argues at length that the Battle was decisive in just this sense: there were no (likely) alternative events that, had it not been for the Greek victory at Salamis, would have ensured the preservation of Hellenistic values. To use a new example, discussions about whether Archduke Franz Ferdinand's assassination caused the First World War revolve around whether the killing made a difference to the event, not whether it was part of a chain of events that led to the outbreak of the war - with other potential causes in the offing. Weber-causation is therefore not necessary for causation either.

Do we have to conclude that the historians' method of causal inference is simply mistaken? In my view, no. It is certainly true that Weber-causation is different from ordinary causation. But which concept is more appropriate depends on the purpose pursued. Historians often aim at determining the historical significance of a person or an act, considered as singular event, or the effectiveness of a policy, in which case the event is considered as an instance of a type. In both cases differencemaking, not actual causing, is important. The fact that it was only due to a sole individual's actions that Greece survived and thus that the rise of the West hung by a thread has been used as an argument against triumphalists who would like to believe that Western values had to become dominant because of their intrinsic superiority. Had Hellenism prevailed no matter what, even if 'Themistocles' actions in fact led to the survival of Western ideas, the argument could not be made. Similarly, a policy that does not make a difference to an outcome of interest is useless and probably harmful because of its costs.

On the other hand, especially in the policy context it does not matter whether an event that makes a difference is an actual cause of the outcome of interest. Suppose it was not the diplomacy of the 
appeasement policy that made Hitler occupy first the Sudetenland and then the remaining Czechoslovakia but rather the weakness of the British military. Suppose further that rearmament is a cause of deterrence. Then, if implementing anti-appeasement policy has to go through rearming first, it simply doesn't matter whether it is the military threat or the diplomacy which is effective. Again, therefore, what matters is the difference making not the causing. 
Bibliography

Hanson, Victor Davis 2006, 'A Stillborn West? Themistocles at Salamis, 480 BC', in Philip Tetlock, Richard Ned Lebow and Geoffrey Parker (eds), Unmaking the West: "What-if?" Scenarios That Rewrite World History, Ann Arbor (MI): University of Michigan Press: 47-89

Khong, Yuen Foong 1996, 'Confronting Hitler and Its Consequences', in Philip Tetlock and Aaron Belkin (eds), Counterfactual Thought Experiments in World Politics, Princeton (NJ): Princeton University Press: 95-118

Lebow, Richard Ned and Janice Gross Stein 1996, 'Back to the Past: Counterfactuals and the Cuban Missle Crisis', in Philip Tetlock and Aaron Belkin (eds), Counterfactual Thought Experiments in World Politics, Princeton (NJ): Princeton University Press: 119-48

Lewis, David 1973, 'Causation', Journal of Philosophy 70(8): 556-67

Lewis, David 1979, 'Counterfactual Dependence and Time’s Arrow', Noûs 13(4): 455-76

Tetlock, Philip and Aaron Belkin (eds) 1996, Counterfactual Thought Experiments in World Politics: Logical, Methodological and Psychological Perspectives, Princeton (NJ): Princeton University Press

Weber, Max 1949/1905, 'Objective Possibility and Adequate Causation in Historical Explanation', in Max Weber, Edward Shils and Henry Finch (eds), The Methodology of the Social Sciences, Glencoe (IL): Free Press: 164-88 